\title{
Resting heart rate and incident heart failure and cardiovascular mortality in older adults: role of inflammation and endothelial dysfunction: the PROSPER study
}

\author{
David Nanchen ${ }^{1,2 *}$, David J. Stott ${ }^{3,4}$, Jacobijn Gussekloo ${ }^{5}$, Simon P. Mooijaart ${ }^{2,6}$, \\ Rudi G.J. Westendorp ${ }^{2,7}$, J. Wouter Jukema ${ }^{8}$, Peter W. Macfarlane ${ }^{3}$, Jacques Cornuz ${ }^{1}$, \\ Nicolas Rodondi ${ }^{9}$, Brendan M. Buckley ${ }^{10}$, Ian Ford ${ }^{11}$, Naveed Sattar ${ }^{3}$, and \\ Anton J.M. de Craen ${ }^{2,7}$, on behalf of the PROSPER Group
}

\begin{abstract}
${ }^{1}$ Department of Ambulatory Care and Community Medicine, University of Lausanne, Lausanne, Switzerland; ${ }^{2}$ Department of Gerontology and Geriatrics, Leiden University Medical Center, The Netherlands; ${ }^{3}$ Institute of Cardiovascular and Medical Sciences, University of Glasgow, Glasgow, UK; ${ }^{4}$ Faculty of Medicine, University of Glasgow, Glasgow, UK; ${ }^{5}$ Department of Public Health and Primary Care, Leiden University Medical Center, Leiden, The Netherlands; ${ }^{6}$ Institute for Evidence-Based Medicine in Old Age (IEMO), Leiden, The Netherlands; ${ }^{7}$ Netherlands Consortium for Healthy Aging, Leiden University Medical Center, Leiden, The Netherlands; ${ }^{8}$ Department of Cardiology, Leiden University Medical Center, Leiden, The Netherlands; ${ }^{9}$ Department of General Internal Medicine, University of Bern, Bern, Switzerland; ${ }^{10}$ Department of Pharmacology and Therapeutics, Cork University Hospital, Cork, Ireland; and ${ }^{11}$ Robertson Centre for Biostatistics, University of Glasgow, Glasgow, UK
\end{abstract}

Received 7 October 2012; revised 26 October 2012; accepted 2 November 2012

\begin{abstract}
Aims
Resting heart rate is a promising modifiable cardiovascular risk marker in older adults, but the mechanisms linking heart rate to cardiovascular disease are not fully understood. We aimed to assess the association between resting heart rate and incident heart failure (HF) and cardiovascular mortality, and to examine whether these associations might be attributable to systemic inflammation and endothelial dysfunction.

Methods We studied 4084 older adults aged 70-82 years with known cardiovascular risk factors or previous cardiovascular and results disease, without pre-existing HF or beta-blockers in the PROSPER study. Over a 3.2-year follow-up period, we examined incident HF hospitalization and cardiovascular mortality according to resting heart rate, along with C-reactive protein (CRP), interleukin-6 (IL-6), tissue plasminogen activator (tPA), and von Willebrand factor ( $\mathrm{vWf}$ ). Mean heart rate was 67 b.p.m. for men and 70 b.p.m. for women. CRP, IL-6, tPA, and vWf levels were all positively correlated with heart rate. After multivariate adjustment, heart rate was associated with HF hospitalization [hazard ratio (HR) 1.78 for highest vs. lowest distribution third, $95 \%$ confidence interval $(\mathrm{Cl}) 1.21-2.63, P=0.003$ ] and cardiovascular mortality (HR 1.74, 95\% Cl 1.23-2.47, $P=0.002)$. Further adjustment for both IL-6 and vWf levels decreased $\mathrm{HR}$ to $1.60(95 \% \mathrm{Cl} 1.08-2.38, P=0.020)$ for $\mathrm{HF}$ and to $1.50(95 \% \mathrm{Cl} 1.04-2.15, P=0.028)$ for cardiovascular mortality.
\end{abstract}
Conclusion Increased heart rate is associated with increased systemic inflammation and endothelial dysfunction. These factors are likely to contribute to, but do not fully explain, the risk of HF and cardiovascular death associated with increased heart rate in older age.

Keywords

Cardiovascular • Heart rate • Inflammation • Endothelium • Geriatrics • Prevention/screening

\footnotetext{
* Corresponding author. University of Lausanne, Department of Ambulatory Care and Community Medicine, Rue du Bugnon 44, CH-1011 Lausanne, Switzerland. Tel: + 412131460 53, Fax: +412131461 08, Email: david.nanchen@chuv.ch

Published on behalf of the European Society of Cardiology. All rights reserved. (C) The Author 2012. For permissions please email: journals.permissions@oup.com.
} 


\section{Introduction}

For $>20$ years, observational studies have reported an association between elevated resting heart rate and cardiovascular disease. ${ }^{1,2}$ The underlying explanations for these associations are still unclear, and uncertainty remains about the causal role of heart rate in the development of cardiovascular disease. ${ }^{3}$ However, resting heart rate appears to be a promising and modifiable cardiovascular risk factor in older adults, in whom traditional cardiovascular risk factors such as cholesterol level and blood pressure have a lower predictive capacity. ${ }^{4}$

There are many hypothetical mechanisms through which elevated heart rate might directly affect cardiovascular or heart failure risk, including systemic inflammation and endothelial dysfunction. ${ }^{5}$ Systemic inflammation as measured by inflammatory markers such as C-reactive protein (CRP) or interleukin-6 (IL-6) is an important factor in the pathogenesis of cardiovascular disease. ${ }^{6,7}$ Previous cross-sectional studies have suggested a link between heart rate and systemic inflammation through a mechanism related to autonomic imbalance., 8 Markers of endothelial dysfunction, as measured by von Willebrand factor ( $\mathrm{vWf}$ ) or tissue plasminogen activator (tPA), have gained interest in the pathogenesis of cardiovascular disease, ${ }^{10}$ and might be associated with resting heart rate. ${ }^{11}$ Thus, the interrelationship between resting heart rate, systemic inflammation, and endothelial dysfunction might play a key role in the development of cardiovascular disease, and previous epidemiological data have failed to demonstrate a cause-effect relationship because of potential residual confounding. ${ }^{12,13}$

Therefore, we studied the association between resting heart rate, incident heart failure, and cardiovascular mortality in the PROSPER study, a large prospective study of older men and women, and examined whether any associations might be attributable to inflammation or endothelial dysfunction.

\section{Methods}

\section{Study population}

Participants were part of the PROSPER trial designed to examine the benefits of pravastatin vs. placebo in adults aged 70-82 years old. ${ }^{14}$ Details of the design, data collection, and eligibility criteria have been previously described. ${ }^{15}$ Briefly, 5804 individuals aged 70-82 years, and sufficiently mobile to attend visits at their general practitioner's office or the study centre, were randomized to $40 \mathrm{mg}$ pravastatin or placebo in The Netherlands, Scotland, and Ireland. Only participants with a history of vascular disease, defined as coronary, cerebral, or peripheral artery disease, or those with known cardiovascular risk factors, such as smoking, hypertension, or diabetes, were enrolled. Participants with symptomatic congestive heart failure (NYHA functional class III or IV) or ECG evidence of AF were excluded, as well as those with poor cognitive function [Mini Mental State Examination (MMSE) score <24]. The Medical Ethics Committee of all centres approved the study, and informed consent was obtained from all participants.

From the original study sample of 5804 individuals, we excluded 120 participants with missing heart rate measurements at baseline, four participants with baseline AF (who were protocol violators), and 149 taking antiarrhythmic drugs and 1447 taking beta-blockers, because of the effects of antiarrhythmic drugs and beta-blockers on heart rate. Hence, the final sample of our study was 4084 participants.

\section{Resting heart rate}

Resting heart rate (b.p.m.) was automatically measured from a 12-lead ECG recorded in the morning as part of the first enrolment visit, along with fasting venous blood sample collection, to limit circadian variability. $^{15,16}$ All ECGs were interpreted using the same software, which produced all measurements including heart rate, as previously described. $^{16}$

\section{Inflammation and endothelial dysfunction markers}

At baseline, vWf, tPA, and IL-6 were measured with an enzyme-linked immunosorbent assay; Biopool $A B$ was used for $\mathrm{tPA}$, rabbit antihuman polyclonal antibodies (Dako) were used for VWf, and R\&D Systems was used for IL-6, as previously reported. ${ }^{17,18}$ CRP was measured at baseline with an automated particle-enhanced immunoturbidimetric assay (Roche UK). ${ }^{17}$

\section{Heart failure hospitalization and cardiovascular mortality}

We examined incident heart failure hospitalization and cardiovascular mortality as previously defined. ${ }^{14}$ Heart failure hospitalizations were defined based on a combination of symptoms (e.g. shortness of breath) and signs, including chest radiograph with fluid congestion or echocardiogram with severely diminished LV function. ${ }^{15}$ Cardiovascular mortality was the combined endpoint of coronary heart disease death, fatal stroke, and other vascular death. All outcomes were adjudicated by an expert committee blinded to randomized study medication and using pre-defined criteria. $^{14}$

\section{Baseline covariates}

Diabetes at baseline was defined as self-reported diagnosis, use of antidiabetic drugs, or as fasting blood glucose of $\geq 7.0 \mathrm{mmo} / \mathrm{L}$, or $\leq 11.1 \mathrm{mmol} / \mathrm{L}$ when fasting status was uncertain. ${ }^{15}$ Smoking was defined as never, current, or former. Baseline lipids, creatinine, estimated glomerular filtration rate (eGFR), thyroid-stimulating hormone (TSH), blood pressure, and body mass index (BMI) measurements, education, alcohol intake, MMSE score, and medication use were assessed as previously reported. ${ }^{14,15,19,20}$

\section{Statistical analyses}

Resting heart rate values were grouped into thirds of their distribution, as pre-defined beforehand. This was done separately for women and men because women have a higher resting heart rate than men. ${ }^{21}$ One-way analysis of variance (ANOVA) and $\chi^{2}$ tests were used for group comparisons. Covariates associated with heart rate were additionally examined in a multivariate regression model with stepwise forward selection. We applied a log transformation for CRP and IL-6 concentrations, and report geometric means, because of right-skewed distribution. Kaplan-Meier curves were used to illustrate cumulative incidence of heart failure and survival graphically. The associations between gender-specific heart rate thirds and the endpoints were examined using age- and multivariate-adjusted Cox proportional hazards models, with the lowest heart rate group as the reference group. $P$-values were computed by introducing heart rate as a continuous variable in each model. For the multivariate basic model, potential confounders were determined by biological plausibility, and we retained age, smoking status, baseline diabetes, history of vascular disease, history of angina, hypertension, BMI, HDL-cholesterol, TSH, 
Table I Baseline characteristics of the 4084 PROSPER participants according to gender-specific heart rate thirds

\begin{tabular}{|c|c|c|c|c|}
\hline & $\begin{array}{l}\text { Low heart rate third } \\
(n=1391)\end{array}$ & $\begin{array}{l}\text { Middle heart rate third } \\
(n=1421)\end{array}$ & $\begin{array}{l}\text { High heart rate third } \\
(n=1272)\end{array}$ & $P$-value \\
\hline Heart rate, b.p.m. & $57.5(5.1)$ & $68.5(3.2)$ & $81.8(7.7)$ & \\
\hline \multicolumn{5}{|l|}{ Demographics } \\
\hline Age, years & $75.2(3.3)$ & $75.3(3.4)$ & $75.4(3.4)$ & 0.577 \\
\hline Female, $n(\%)$ & $716(51.5)$ & $714(50.2)$ & $638(50.2)$ & 0.743 \\
\hline Education, years & $15.2(2.1)$ & $15.1(2.0)$ & $15.0(1.9)$ & 0.020 \\
\hline Smoking status, $n(\%)$ & & & & 0.112 \\
\hline Never & $418(30.0)$ & $427(30.0)$ & $404(31.8)$ & \\
\hline Former & $552(39.7)$ & $509(35.8)$ & $460(36.2)$ & \\
\hline Current & $421(30.3)$ & $485(34.1)$ & $408(32.1)$ & \\
\hline Alcohol consumption, drinks/week & $5.2(8.6)$ & $5.5(9.9)$ & $5.5(9.8)$ & 0.629 \\
\hline \multicolumn{5}{|l|}{ Co-morbidities } \\
\hline Hypertension, n (\%) & $745(53.6)$ & $770(54.2)$ & $723(56.8)$ & 0.200 \\
\hline Diabetes, $n(\%)$ & $114(8.2)$ & $170(12.0)$ & $179(14.1)$ & $<0.001$ \\
\hline History of vascular disease, $n(\%)^{a}$ & $616(44.3)$ & $586(41.2)$ & $503(39.6)$ & 0.041 \\
\hline History of coronary artery disease, $n(\%)^{b}$ & $208(14.9)$ & $171(12.0)$ & $179(14.1)$ & 0.069 \\
\hline History of angina, $n(\%)$ & $363(26.1)$ & $321(22.6)$ & $269(21.2)$ & 0.008 \\
\hline History of stroke or TIA, $n(\%)$ & $163(11.7)$ & $163(11.5)$ & $143(11.2)$ & 0.928 \\
\hline History of peripheral artery disease, $n(\%)^{c}$ & $100(7.2)$ & $122(8.6)$ & $119(9.4)$ & 0.412 \\
\hline Lower MMSE score, $n(\%)^{d}$ & $413(29.7)$ & $459(32.3)$ & $439(34.5)$ & 0.028 \\
\hline \multicolumn{5}{|l|}{ Objective measures } \\
\hline Systolic blood pressure, $\mathrm{mmHg}$ & $152.6(20.9)$ & $154.5(21.2)$ & $156.6(21.6)$ & $<0.001$ \\
\hline Diastolic blood pressure, $\mathrm{mmHg}$ & $82.5(10.9)$ & $84.0(11.3)$ & $85.4(11.7)$ & $<0.001$ \\
\hline Weight, kg & $72.4(12.7)$ & $73.3(13.1)$ & $73.2(14.3)$ & 0.142 \\
\hline Height, cm & $165.5(9.4)$ & $165.4(9.7)$ & $164.7(9.4)$ & 0.060 \\
\hline Body mass index, $\mathrm{kg} / \mathrm{m}^{2}$ & $26.4(4.0)$ & $26.7(4.1)$ & $26.9(4.6)$ & 0.004 \\
\hline Total cholesterol, mmol/L & $5.7(0.9)$ & $5.7(0.9)$ & $5.7(0.9)$ & 0.559 \\
\hline LDL-cholesterol' mmol/L & $3.8(0.8)$ & $3.8(0.8)$ & $3.7(0.8)$ & 0.070 \\
\hline HDL-cholesterol, mmol/L & $1.3(0.3)$ & $1.3(0.4)$ & $1.3(0.4)$ & 0.013 \\
\hline Triglycerides, mmol/L & $1.5(0.7)$ & $1.5(0.7)$ & $1.5(0.7)$ & 0.216 \\
\hline Fasting glucose, $\mathrm{mmol} / \mathrm{L}$ & $5.3(1.2)$ & $5.4(1.4)$ & $5.6(1.7)$ & $<0.001$ \\
\hline Creatinine, $\mu \mathrm{mol} / \mathrm{L}$ & $100.5(21.8)$ & $100.4(21.6)$ & $100.8(22.0)$ & 0.882 \\
\hline eGFR, $\mathrm{mL} / \mathrm{min}$ & $60.3(13.8)$ & $60.7(14.2)$ & $60.5(14.7)$ & 0.761 \\
\hline $\mathrm{TSH}, \mathrm{mlU} / \mathrm{L}$ & $2.4(2.2)$ & $2.3(2.1)$ & $2.2(2.0)$ & 0.150 \\
\hline CRP, mg/L & $2.7(2.8)$ & $3.0(3.2)$ & $3.8(3.3)$ & $<0.001$ \\
\hline $\mathrm{IL}-6, \mathrm{pg} / \mathrm{mL}$ & $2.4(1.5)$ & $2.6(1.9)$ & $2.9(2.1)$ & $<0.001$ \\
\hline $\mathrm{tPA}, \mathrm{ng} / \mathrm{mL}$ & $10.5(3.8)$ & $10.7(4.0)$ & $11.3(4.1)$ & $<0.001$ \\
\hline$v W f, I U / d L$ & $137.4(45.2)$ & $141.3(46.3)$ & $146.7(47.7)$ & $<0.001$ \\
\hline \multicolumn{5}{|l|}{ Medication use } \\
\hline Pravastatin, $n(\%)$ & $695(50.0)$ & $732(51.5)$ & $651(51.2)$ & 0.373 \\
\hline Aspirin, $n$ (\%) & $501(36.0)$ & $463(32.6)$ & $399(31.4)$ & 0.029 \\
\hline Nitrates, $n(\%)$ & $262(18.8)$ & $223(15.7)$ & $182(14.3)$ & 0.005 \\
\hline Diuretics, n (\%) & $528(38.0)$ & $526(37.0)$ & $523(41.2)$ & 0.076 \\
\hline Calcium channel blockers, $n(\%)$ & $378(21.2)$ & $350(24.6)$ & $319(25.1)$ & 0.261 \\
\hline ACE inhibitors, $n(\%)$ & $229(16.5)$ & $228(16.1)$ & $244(19.2)$ & 0.068 \\
\hline ARBs, $n(\%)$ & $33(2.4)$ & $34(2.4)$ & $25(2.0)$ & 0.707 \\
\hline Other antihypertensive drugs, $n(\%)$ & $43(3.1)$ & $56(3.9)$ & $61(4.8)$ & 0.077 \\
\hline Thyroid hormone, $n(\%)$ & $67(4.8)$ & $69(4.9)$ & $44(3.4)$ & 0.139 \\
\hline
\end{tabular}

Data are given as mean (standard deviation) unless otherwise indicated.

CRP, C-reactive protein; eGFR, estimated glomerular filtration rate; IL-6, interleukin-6; MMSE, Mini Mental State Examination; TSH, thyroid-stimulating hormone; TIA, transient ischaemic attack; tPA, tissue plasminogen activator; vWf, von Willebrand factor.

${ }^{a} V$ ascular disease defined as history of coronary, cerebral, or peripheral artery disease.

${ }^{b}$ Coronary artery disease defined as history of myocardial infarction, $\mathrm{PCl}$, or coronary artery bypass surgery.

'Peripheral artery disease defined as history of claudication or peripheral vascular surgery.

dMMSE score of 24-27. Participants with poor cognitive function were excluded (MMSE <24). 
and eGFR. We further adjusted the model for randomization code (pravastatin), and use of aspirin, nitrates, diuretics, ACE inhibitors, and ARBs to account for medication. To assess the effect of inflammation and endothelial dysfunction, we further adjusted the basic model for CRP and IL-6, and with IPA and VWf, respectively. Finally, we examined a multivariate model using the inflammatory marker and the endothelial dysfunction marker with the strongest association (IL-6 and vWf), as well as a multivariate model using all inflammatory and endothelial dysfunction markers. Subgroup analyses were conducted in men and women separately, and in participants with low CRP levels $(<2 \mathrm{mg} / \mathrm{L}$ ), moderate CRP (between 2 and $5 \mathrm{mg} / \mathrm{L}$ ), or elevated CRP levels ( $>5 \mathrm{mg} / \mathrm{L})$, as well as across strata of IL-6, tPA, and $\checkmark W f$ thirds, and groups defined by the use of statin or placebo. The significance of the multiplicative interaction term between heart rate as a continuous variable and subgroups in the multivariate model was reported. We further stratified our results in adults without and with pre-existing cardiovascular disease or diabetes. All analyses were conducted using Stata 12.0 (Stata Corp, College Station, TX, USA), all statistical tests were two-sided, and $P<0.05$ was considered statistically significant.

\section{Results}

Mean age of the participants was 75 years and $51 \%$ were female. Table 1 reports baseline characteristics of the study population, over thirds of heart rate. In men, resting heart rate values were $<61$ b.p.m. for the first third, 62-71 b.p.m. for the second, and $\geq 72$ b.p.m. for the third. In women, cut-offs were $<65$ b.p.m., $66-74$ b.p.m., and $\geq 75$ b.p.m., respectively. Both inflammatory markers (CRP and IL-6) and endothelial dysfunction markers (tPA and $\mathrm{vWf}$ ) were significantly increased over thirds of resting heart rate. Participants in the highest heart rate third were also more likely to have diabetes, a higher blood pressure, and a higher BMI compared with participants in the lowest heart rate group. In contrast, they were less likely to have pre-existing vascular disease, or a history of angina, and to be treated by aspirin or nitrates. In multivariate analyses, CRP, IL-6, tPA, and $\mathrm{VWf}$ all remained independently associated with resting heart rate (all $P<0.001$; Supplementary material, Table S1).
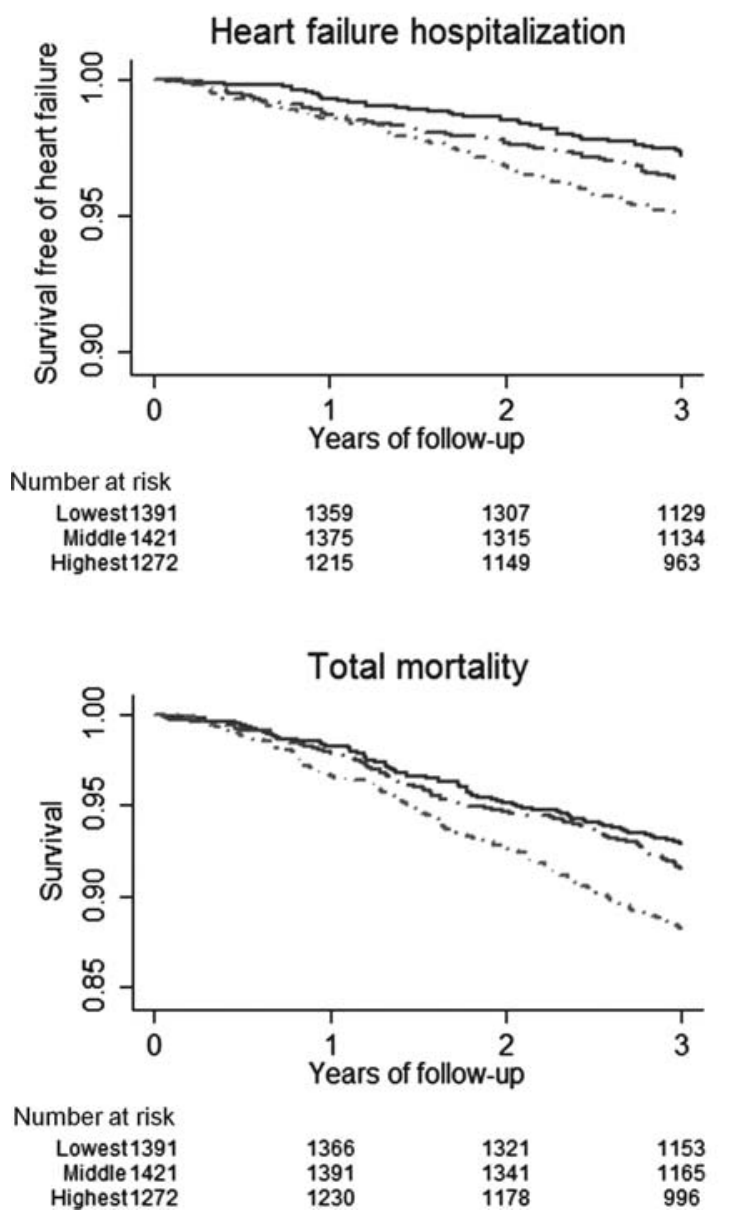
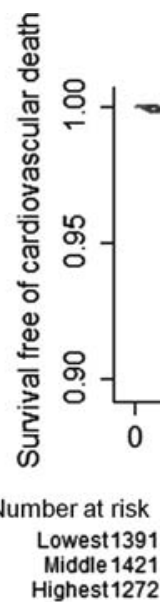

\section{Cardiovascular mortality}

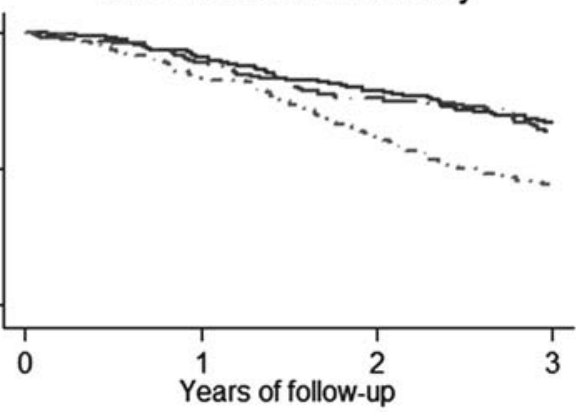

$\begin{array}{ccc}1366 & 1321 & 1153 \\ 1391 & 1341 & 1165 \\ 1230 & 1178 & 996\end{array}$

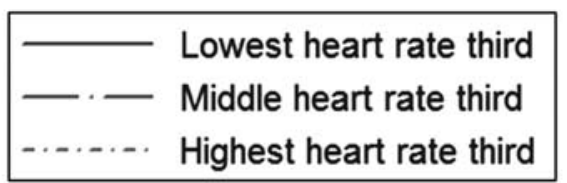

Figure I Cumulative incidence of heart failure hospitalization and cardiovascular mortality over the 3-year follow-up period depending on sex-specific heart rate groups. 
The incidence of heart failure hospitalization was 12.9 per 1000 person-years [95\% confidence interval $(\mathrm{Cl}) 11.1-15.0$ ] and was higher in men (14.4 per 1000 man-years, 95\% Cl 11.7-17.7) than in women (11.5 per 1000 woman-years, 95\% Cl 9.2-14.4), although without statistical difference (log-rank test $P=0.14$ ). A resting heart rate in the highest third vs. the lowest third was associated with a similar increased risk of heart failure hospitalization [multivariate-adjusted hazard ratio $(\mathrm{HR})$ of $1.78,95 \% \mathrm{Cl} 1.21-$ 2.63, $P=0.003]$ and cardiovascular mortality $(\mathrm{HR} 1.74,95 \% \mathrm{Cl}$ 1.23-2.47, $P=0.002$ ) (Figure 1, Table 2). Adults in the middle heart rate group also had a higher risk of heart failure and cardiovascular mortality, but without reaching statistical significance, compared with those in the lowest heart rate group. The multivariate-adjusted HR per b.p.m. higher heart rate was 1.023 $(95 \% \mathrm{Cl} 1.010-1.036)$ for heart failure and $1.022(95 \% \mathrm{Cl}$ 1.010-1.033) for cardiovascular mortality. Similar figures were found after further adjustment for medication, including the randomization allocation for statin use or placebo. Further adjustment for inflammatory markers, CRP or IL-6, and further adjustment for endothelial dysfunction markers, tPA or vWf, only slightly decreased HRs (Table 2). Further adjustment for both IL-6 and vWf levels decreased the HR (highest vs. lowest third of heart rate) for heart failure to $1.60(95 \% \mathrm{Cl} 1.08-2.38), p=0.020$, and the HR for cardiovascular mortality to $1.50(95 \% \mathrm{Cl} 1.04-$ 2.15), $P=0.028$.

\section{Stratified analyses}

The associations between resting heart rate and heart failure or cardiovascular mortality reached statistical significance in men only, but there was no significant interaction of gender on the association between heart rate and heart failure or cardiovascular mortality (Figure 2). For one unit increase in heart rate, a similar

Table 2 Risk of heart failure and cardiovascular mortality depending on resting heart rate

\begin{tabular}{|c|c|c|c|c|}
\hline & $\begin{array}{l}\text { Low heart rate third } \\
(n=1391)\end{array}$ & $\begin{array}{l}\text { Middle heart rate third } \\
(n=1421)\end{array}$ & $\begin{array}{l}\text { High heart rate third } \\
(n=1272)\end{array}$ & $P$-value \\
\hline \multicolumn{5}{|l|}{ Heart failure hospitalization } \\
\hline No. of events & 43 & 57 & 67 & \\
\hline Incidence rate, per 1000 person-years & 9.6 & 12.6 & 17.0 & \\
\hline Age-adjusted HR (95\% Cl) & 1.00 (referent) & $1.30(0.88-1.94)$ & $1.75(1.19-2.57)$ & $<0.001$ \\
\hline Multivariate-adjusted HR $(95 \% \mathrm{Cl})^{\mathrm{a}}$ & 1.00 (referent) & $1.32(0.88-1.96)$ & $1.78(1.21-2.63)$ & 0.001 \\
\hline $\begin{array}{l}\text { Additional adjustment for } \\
\text { treatment }{ }^{\mathrm{b}}\end{array}$ & 1.00 (referent) & $1.36(0.91-2.02)$ & $1.80(1.22-2.65)$ & 0.001 \\
\hline Additional adjustment for CRP & 1.00 (referent) & $1.31(0.88-1.96)$ & $1.75(1.19-2.60)$ & 0.001 \\
\hline Additional adjustment for IL-6 & 1.00 (referent) & $1.28(0.86-1.92)$ & $1.64(1.11-2.44)$ & 0.003 \\
\hline Additional adjustment for tPA & 1.00 (referent) & $1.25(0.83-1.88)$ & $1.82(1.23-2.70)$ & $<0.001$ \\
\hline Additional adjustment for $v W f$ & 1.00 (referent) & $1.24(0.82-1.86)$ & $1.75(1.18-2.58)$ & 0.001 \\
\hline $\begin{array}{l}\text { Additional adjustment for both IL-6 } \\
\text { and vWf }\end{array}$ & 1.00 (referent) & $1.22(0.81-1.83)$ & $1.60(1.08-2.38)$ & 0.004 \\
\hline $\begin{array}{l}\text { Additional adjustment for all } \\
\text { markers }{ }^{c}\end{array}$ & 1.00 (referent) & $1.20(0.79-1.80)$ & $1.62(1.09-2.41)$ & 0.003 \\
\hline \multicolumn{5}{|l|}{ Cardiovascular mortality } \\
\hline No. of deaths & 53 & 63 & 84 & \\
\hline Incidence rate, per 1000 person-years & 11.7 & 13.7 & 20.9 & \\
\hline Age-adjusted HR (95\% Cl) & 1.00 (referent) & $1.18(0.82-1.69)$ & $1.78(1.26-2.51)$ & $<0.001$ \\
\hline Multivariate-adjusted HR $(95 \% \mathrm{Cl})^{\mathrm{a}}$ & 1.00 (referent) & $1.13(0.78-1.64)$ & $1.74(1.23-2.47)$ & $<0.001$ \\
\hline $\begin{array}{l}\text { Additional adjustment for } \\
\text { treatment }^{\mathrm{b}}\end{array}$ & 1.00 (referent) & $1.15(0.79-1.66)$ & $1.73(1.22-2.45)$ & 0.001 \\
\hline Additional adjustment for CRP & 1.00 (referent) & $1.11(0.76-1.60)$ & $1.61(1.13-2.30)$ & 0.003 \\
\hline Additional adjustment for IL-6 & 1.00 (referent) & $1.11(0.76-1.60)$ & $1.57(1.10-2.24)$ & 0.004 \\
\hline Additional adjustment for tPA & 1.00 (referent) & $1.11(0.77-1.62)$ & $1.67(1.17-2.38)$ & 0.001 \\
\hline Additional adjustment for $v W f$ & 1.00 (referent) & $1.14(0.78-1.66)$ & $1.65(1.15-2.36)$ & 0.001 \\
\hline $\begin{array}{l}\text { Additional adjustment for both IL-6 } \\
\text { and } v W f\end{array}$ & 1.00 (referent) & $1.08(0.74-1.58)$ & $1.50(1.04-2.15)$ & 0.009 \\
\hline $\begin{array}{l}\text { Additional adjustment for all } \\
\text { markers }{ }^{c}\end{array}$ & 1.00 (referent) & $1.05(0.72-1.54)$ & $1.48(1.03-2.13)$ & 0.010 \\
\hline
\end{tabular}

$\mathrm{Cl}$, confidence interval; CRP, C-reactive protein; HR, hazard ratio; IL-6, interleukin-6; tPA, tissue plasminogen activator; vWf, von Willebrand factor. ${ }^{a}$ Basic model: adjusted for age, smoking status, diabetes, history of cardiovascular disease, history of angina, hypertension, body mass index, HDL-cholesterol, thyroid-stimulating hormone, and glomerular filtration rate.

bBasic model plus additional adjustment for randomization group (pravastatin), aspirin, nitrate, calcium channel blocker, diuretic, ACE inhibitor, and ARB use. 'Basic model plus additional adjustment for CRP, IL-6, tPA, and vWf. 


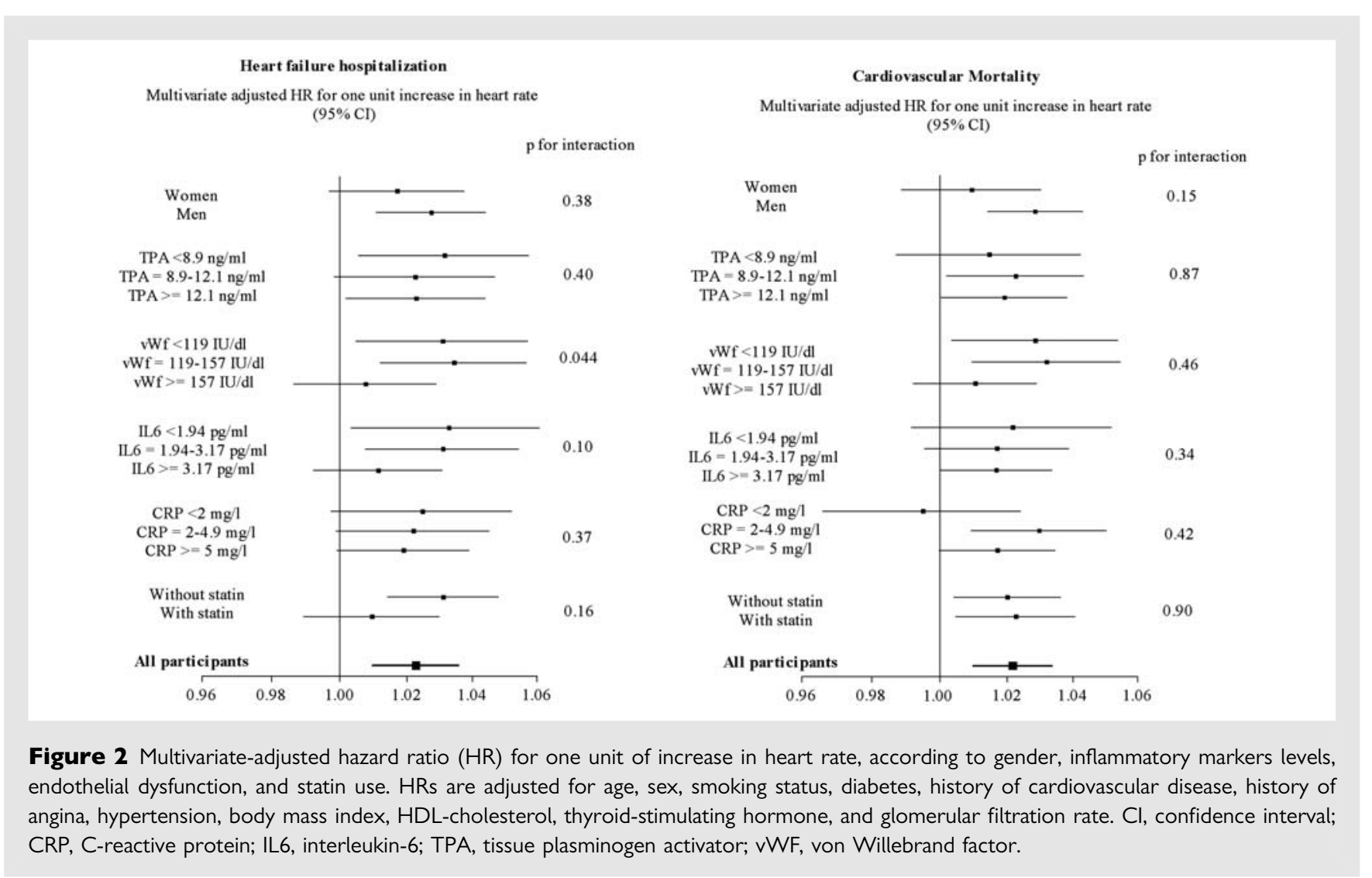

$2 \%$ increased risk for heart failure and cardiovascular mortality was found across strata of inflammatory marker levels. Similar patterns of risk for heart failure and cardiovascular mortality were also found across strata of endothelial dysfunction markers. In the subgroup with CRP levels $<2 \mathrm{mg} / \mathrm{L}$, a lower risk of cardiovascular mortality was found along with elevation of resting heart rate, but the interaction term was not significant $(P=0.42)$.

The increased heart failure and cardiovascular mortality risk associated with elevated heart rate were present in older adults without cardiovascular disease or diabetes, as well as in those with pre-existing cardiovascular disease or diabetes, and further adjustment for inflammatory markers or endothelial dysfunction only slightly modified the estimates (Figure 3).

\section{Discussion}

In older adults at high cardiovascular risk, an elevated resting heart rate was associated with an increased risk of incident heart failure hospitalization and cardiovascular mortality. This increased risk was independent of traditional cardiovascular risk factors and was only partially explained by inflammatory and endothelial dysfunction markers. The association was present in both the presence and absence of statin use, as well as pre-existing cardiovascular disease or diabetes. To our knowledge, our study is the first to report an independent association between heart rate and heart failure and cardiovascular mortality, in which markers of inflammation and endothelial dysfunction were simultaneously assessed. These results emphasize the strength of resting heart rate "per se' as a cardiovascular risk factor among older adults, and adds important information to disentangle the pathophysiological mechanisms linking resting heart rate and cardiovascular disease.

Resting heart rate is considered as a marker of autonomic nervous system activity, and an elevated heart rate implies sympathetic hyperactivity. ${ }^{5}$ This imbalance has been proposed to explain the development of cardiovascular disease, but the exact mechanisms are still uncertain. ${ }^{3}$ Inflammatory markers such as CRP or IL-6 levels have been related to the autonomic nervous system in previous cross-sectional studies, suggesting that inflammation might modify heart rate by impacting on the autonomic nervous system. ${ }^{8,9}$ Our results confirm the close relationship between resting heart rate and systemic inflammation, beyond fundamental determinants of heart rate, such as gender or height, environmental factors such as smoking, blood pressure, hyperlipidaemia, diabetes, or other expected factors such as TSH levels. Although inflammatory markers were independently associated with heart rate, we additionally show that heart rate may influence the risk of cardiac disease by pathways other than inflammation. Thus, systemic inflammation may not be the only explanatory factor in the worse prognosis of older adults with elevated heart rate.

Endothelial dysfunction generated by oscillatory shear stress due to an elevated heart rate has also been identified as a biological contributor to explain the development of cardiovascular disease. ${ }^{3,5}$ tPA is involved in the conversion of plasminogen to plasmin, and VWF mediates platelet adhesion and thrombosis. Both tPA and vWf are produced by endothelial cells and can be considered as markers of endothelial dysfunction. ${ }^{22,23}$ It has been 


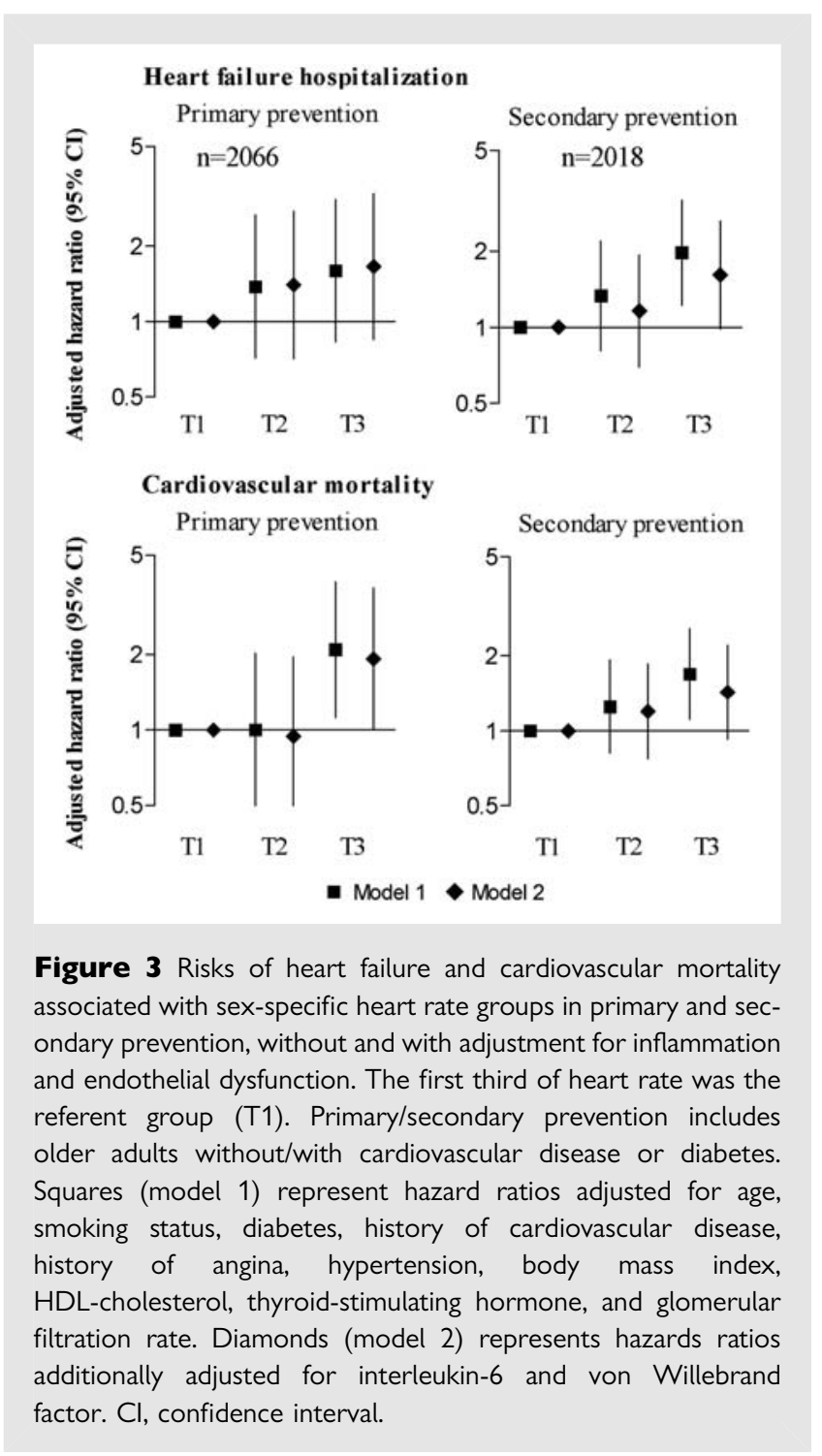

suggested that elevated heart rate could promote cardiac disease through blood flow modification in the arteries, increasing oscillatory endothelial shear stress, and influencing arterial stiffness and LV afterload. ${ }^{3}$ In our study, resting heart rate was associated with endothelial dysfunction independently of heart rate determinants and systemic inflammation. These results are in line with the hypothesis that haemodynamic mechanisms, such as oscillatory shear stress, are mediators of the association between heart rate and endothelial dysfunction. ${ }^{5,24}$ Over the study follow-up period, we found no consistent evidence that endothelial dysfunction could fully explain the link between resting heart rate and cardiac disease. However, for values of $\mathrm{vWf}>156 \mathrm{lU} / \mathrm{dL}$, the increased risk of cardiac disease associated with heart rate was less pronounced, and we found a significant interaction term between heart rate as a continuous variable and VWF levels $(P=0.044)$ for the risk of heart failure. This result might be due to a chance event, because when using heart rate tertile-based categories, the interaction term between heart rate and $v W f$ levels was not significant $(P=0.41)$.
Resting heart rate is easily measured in clinical practice and systematically recorded along with blood pressure measurement. In older adults, traditional cardiovascular risk factors such as cholesterol level and blood pressure have a lower or potentially different predictive association, ${ }^{4}$ while we confirmed the increased cardiac risk in older adults with elevated heart rate. This increased risk was related to the level of heart rate, and only partially mediated by systemic inflammation and endothelial dysfunction. Therefore, heart rate appears to be a potential therapeutic target to reduce the cardiovascular risk in older adults. Our study supports the rationale of designing clinical trials to test a specific heart ratelowering intervention to reduce the cardiac risk of older adults with elevated resting heart rate. Many older adults with orthostatic hypotension and elevated risk of falls a have contra-indication to beta-blockers, and the risk of side effects with beta-blockers prescribed as a preventive therapy for an elevated heart rate might outweigh the benefits. Ivabradine is a new drug that specifically inhibits the sinus node without influencing blood pressure. ${ }^{25,26}$ In the SHIFT trail, the benefit of reducing heart rate with ivabradine was the greatest with the highest heart rate levels, ${ }^{25}$ and ivabradine is only licensed for heart failure patient with heart rate $>75$ b.p.m. In our study of older adults at high cardiovascular risk, $25 \%$ of participants had a resting heart rate $>75$ b.p.m. Future studies should now evaluate the use of ivabradine among older adults with elevated baseline heart rate.

Strengths of our data include the large population of older men and women with biological phenotyping of subclinical inflammation and endothelial dysfunction, the adjudication of clinical events with well-defined criteria, and the possibility to compare the cardiovascular impact of resting heart rate in statin and non-statin users. ${ }^{14}$ The use of statins seemed to modify the risk of heart failure associated with increasing heart rate, but the interaction term did not reach statistical difference $(P=0.16)$. Experimental studies have shown that statins can influence sympathetic activity. ${ }^{27}$ However, since statins had no effect on the risk of heart failure in the PROSPER trial during the study period, it seems unlikely that the association between heart rate and heart failure is influenced by statins. ${ }^{14}$ Our study also has some limitations. First, we excluded a high number of participants using beta-blockers (26\%) from the original PROSPER sample. The use of beta-blockers was elevated because participants were selected according to the presence of cardiovascular risk factors or cardiovascular disease. However, beta-blocker use might be an important confounder of the association between heart rate and cardiovascular disease, which would have greatly limited the interpretation of the results. In our study of older adults at high cardiovascular risk, those with symptomatic congestive heart failure were excluded. However, our population certainly included participants with subclinical LV dysfunction. As we did not characterize these individuals with echocardiography at baseline, we cannot discard that an elevated heart rate was a sign of mild heart failure, and not primarily an autonomic nervous system issue. Further research about resting heart rate is therefore merited along with BNP and echocardiography measurements or in healthier older populations. The biological assessment of endothelial dysfunction was undertaken with haemostatic/ thrombotic markers released by endothelial cells with an established effect on vascular homeostasis, such as a platelet-activating 
(vWf) and profibrinolytic effect (tPA). ${ }^{22,23}$ However, these markers might not be appropriate to assess other important processes linked to endothelial damage, such as adhesion and migration of leucocytes. Further studies should assess the role of cell adhesion molecules in the observed associations. ${ }^{6}$ Finally, although inflammation and endothelial dysfunction markers were measured at the baseline visit along with baseline heart rate, they were measured only once, and this might not reflect the chronic underlying conditions of the participants.

In conclusion, through a mechanism only partially linked to systemic inflammation and endothelial dysfunction, resting heart rate was an independent marker of incident heart failure and cardiovascular mortality in old age.

\section{Supplementary material}

Supplementary material is available at European Journal of Heart Failure online.

\section{Funding}

A Swiss National Science Foundation grant [PBLAP3-132943 to D.N.]; The Netherlands Genomics Initiative/Netherlands Organization for scientific research [NGI/NWO 05040202 to R.G.W. and A.J.M.]; Netherlands Consortium for Healthy Aging [NCHA 050-060-810 to R.G.W. and A.J.M.]. The original PROSPER study was supported by an unrestricted, investigator initiated grant from Bristol-Myers Squibb, USA. Measurements of tissue plasminogen activator and von Willebrand factor were supported by a grant from the Scottish Executive Chief Scientist Office [CZG/4/306]. The sponsors of the study had no role in study design, data collection, data analysis, data interpretation, or writing of this report.

\section{Conflict of interest: none declared.}

\section{References}

1. Diaz A, Bourassa MG, Guertin MC, Tardif JC. Long-term prognostic value of resting heart rate in patients with suspected or proven coronary artery disease. Eur Heart J 2005;26:967-974.

2. Kannel WB, Kannel C, Paffenbarger RS, Cupples LA. Heart rate and cardiovascular mortality: the Framingham Study. Am Heart J 1987;113:1489-1494.

3. Fox KM, Ferrari R. Heart rate: a forgotten link in coronary artery disease? Nat Rev Cardiol 2011;8:369-379.

4. de Ruijter W, Westendorp RG, Assendelft WJ, den Elzen WP, de Craen AJ, le Cessie S, Gussekloo J. Use of Framingham risk score and new biomarkers to predict cardiovascular mortality in older people: population based observational cohort study. BMJ 2009;338:a3083.

5. Custodis F, Schirmer SH, Baumhäkel M, Heusch G, Böhm M, Laufs U. Vascular pathophysiology in response to increased heart rate. J Am Coll Cardiol 2010;56: 1973-1983.

6. Hansson GK. Inflammation, atherosclerosis, and coronary artery disease. N Engl J Med 2005;352:1685-1695.

7. Weber C, Noels $H$. Atherosclerosis: current pathogenesis and therapeutic options. Nat Med 2011;17:1410-1422.

8. Lampert R, Bremner JD, Su S, Miller A, Lee F, Cheema F, Goldberg J, Vaccarino V. Decreased heart rate variability is associated with higher levels of inflammation in middle-aged men. Am Heart J 2008;156:e751-e757.
9. Rogowski O, Shapira I, Shirom A, Melamed S, Toker S, Berliner S. Heart rate and microinflammation in men: a relevant atherothrombotic link. Heart 2007;93: 940-944.

10. Landmesser $\mathrm{U}$, Hornig B, Drexler $\mathrm{H}$. Endothelial function: a critical determinant in atherosclerosis? Circulation 2004;109:I127-II33.

11. Brotman DJ, Bash LD, Qayyum R, Crews D, Whitsel EA, Astor BC, Coresh J. Heart rate variability predicts ESRD and CKD-related hospitalization. J Am Soc Nephrol 2010;21:1560-1570.

12. Sajadieh A, Nielsen OW, Rasmussen V, Hein HO, Hansen JF. C-reactive protein, heart rate variability and prognosis in community subjects with no apparent heart disease. J Intern Med 2006;260:377-387.

13. Jensen MT, Marott JL, Allin KH, Nordestgaard BG, Jensen GB. Resting heart rate is associated with cardiovascular and all-cause mortality after adjusting for inflammatory markers: the Copenhagen City Heart Study. Eur J Prev Cardiol 2012;19: 102-108.

14. Shepherd J, Blauw GJ, Murphy MB, Bollen EL, Buckley BM, Cobbe SM, Ford I, Gaw A, Hyland M, Jukema JW, Kamper AM, Macfarlane PW, Meinders AE, Norrie J, Packard CJ, Perry IJ, Stott DJ, Sweeney BJ, Twomey C, Westendorp RG. Pravastatin in elderly individuals at risk of vascular disease (PROSPER): a randomised controlled trial. Lancet 2002;360:1623-1630.

15. Shepherd J, Blauw GJ, Murphy MB, Cobbe SM, Bollen ELEM, Buckley BM, Ford I, Jukema JW, Hyland M, Gaw A, Lagaay AM, Perry IJ, Macfarlane PW, Meinders AE, Sweeney BJ, Packard CJ, Westendorp RGJ, Twomey C, Stott DJ. The design of a prospective study of pravastatin in the elderly at risk (PROSPER). Am J Cardiol 1999;84:1192-1197.

16. Macfarlane PW, Murray H, Sattar N, Stott DJ, Ford I, Buckley B, Jukema JW, Westendorp RGJ, Shepherd J. The incidence and risk factors for new onset atrial fibrillation in the PROSPER study. Europace 2011;13:634-639.

17. Sattar N, Murray HM, Welsh P, Blauw GJ, Buckley BM, Cobbe S, de Craen AJ, Lowe GD, Jukema JW, Macfarlane PW, Murphy MB, Stott DJ, Westendorp RG, Shepherd J, Ford I, Packard CJ. Are markers of inflammation more strongly associated with risk for fatal than for nonfatal vascular events? PLoS Med 2009;6: e1000099.

18. Stott DJ, Robertson M, Rumley A, Welsh P, Sattar N, Packard CJ, Shepherd J, Trompet S, Westendorp RG, de Craen AJ, Jukema JW, Buckley B, Ford I, Lowe GD. Activation of hemostasis and decline in cognitive function in older people. Arterioscler Thromb Vasc Biol 2010;30:605-611.

19. Ford I, Bezlyak V, Stott DJ, Sattar N, Packard CJ, Perry I, Buckley BM, Jukema JW, de Craen AJ, Westendorp RG, Shepherd J. Reduced glomerular filtration rate and its association with clinical outcome in older patients at risk of vascular events: secondary analysis. PLoS Med 2009;6:e16.

20. Nanchen D, Gussekloo J, Westendorp RG, Stott DJ, Jukema JW, Trompet S, Ford I, Welsh P, Sattar N, Macfarlane PW, Mooijaart SP, Rodondi N, de Craen AJ. Subclinical thyroid dysfunction and the risk of heart failure in older persons at high cardiovascular risk. J Clin Endocrinol Metab 2012;97:852-861.

21. Bonnemeier H, Richardt G, Potratz J, Wiegand UK, Brandes A, Kluge N, Katus HA. Circadian profile of cardiac autonomic nervous modulation in healthy subjects: differing effects of aging and gender on heart rate variability. J Cardiovasc Electrophysiol 2003;14:791-799.

22. Lowe GDO, Danesh J, Lewington S, Walker M, Lennon L, Thomson A, Rumley A, Whincup PH. Tissue plasminogen activator antigen and coronary heart disease. Eur Heart J 2004;25:252-259.

23. van Galen KPM, Tuinenburg A, Smeets EM, Schutgens REG. Von Willebrand factor deficiency and atherosclerosis. Blood Rev 2012;26:189-196.

24. Papadaki M, Ruef J, Nguyen KT, Li F, Patterson C, Eskin SG, Mclntire LV, Runge MS. Differential regulation of protease activated receptor-1 and tissue plasminogen activator expression by shear stress in vascular smooth muscle cells. Circ Res 1998;83:1027-1034.

25. Swedberg K, Komajda M, Bohm M, Borer JS, Ford I, Dubost-Brama A Lerebours G, Tavazzi L. Ivabradine and outcomes in chronic heart failure (SHIFT): a randomised placebo-controlled study. Lancet 2010;376:875-885.

26. Fox K, Ford I, Steg PG, Tendera M, Ferrari R. Ivabradine for patients with stable coronary artery disease and left-ventricular systolic dysfunction (BEAUTIFUL): a randomised, double-blind, placebo-controlled trial. Lancet 2008;372:807-816.

27. Herring N, Lee CW, Sunderland N, Wright K, Paterson DJ. Pravastatin normalises peripheral cardiac sympathetic hyperactivity in the spontaneously hypertensive rat. J Mol Cell Cardiol 2011;50:99-106. 